\title{
Melatonin receptors in pancreatic islets: good morning to a novel type 2 diabetes gene
}

\author{
H. Mulder • C. L. F. Nagorny • V. Lyssenko • L. Groop
}

Received: 3 February 2009 / Accepted: 16 March 2009/Published online: 18 April 2009

(C) Springer-Verlag 2009

\begin{abstract}
Melatonin is a circulating hormone that is primarily released from the pineal gland. It is best known as a regulator of seasonal and circadian rhythms; its levels are high during the night and low during the day. Interestingly, insulin levels also exhibit a nocturnal drop, which has previously been suggested to be controlled, at least in part, by melatonin. This regulation can be explained by the proposed inhibitory action of melatonin on insulin release. Indeed, both melatonin receptor $1 \mathrm{~A}$ (MTNR1A) and MTNR1B are expressed in pancreatic islets. The role of melatonin in the regulation of glucose homeostasis has been highlighted by three independent publications based on genome-wide association studies of traits connected with type 2 diabetes, such as elevated fasting glucose, and, subsequently, of the disease itself. The studies demonstrate a link between variations in the MTNRIB gene, hyperglycaemia, impaired early phase insulin secretion and beta cell function. The risk genotype predicts the future development of type 2 diabetes. Carriers of the risk genotype exhibit increased expression of MTNR1B in islets. This suggests that these individuals may be more sensitive to the actions of melatonin, leading to impaired
\end{abstract}

H. Mulder $(\bowtie) \cdot$ C. L. F. Nagorny

Unit of Molecular Metabolism,

Department of Clinical Sciences in Malmö,

Lund University Diabetes Centre,

CRC 91:12,

SE-205 02 Malmö, Sweden

e-mail: hindrik.mulder@med.lu.se

V. Lyssenko • L. Groop

Unit of Diabetes and Endocrinology,

Department of Clinical Sciences in Malmö,

Lund University Diabetes Centre, Clinical Research Center,

Malmö University Hospital,

Malmö, Sweden insulin secretion. Blocking the inhibition of insulin secretion by melatonin may be a novel therapeutic avenue for type 2 diabetes.

Keywords AANAT - Beta cell · Circadian - CLOCK . Genome-wide association · Insulin · Metabolism · SNP . Suprachiasmatic nucleus

$\begin{array}{ll}\text { Abbreviations } \\ \text { AANAT } & \text { Arylalkylamine } N \text {-acetyltransferase } \\ \mathrm{G}_{\mathrm{i}} & \text { Inhibitory G protein } \\ \text { HOMA-B } & \text { HOMA of beta cell function } \\ \text { MTNR1A } & \text { Melatonin receptor 1A } \\ \text { PLC } & \text { Phospholipase C } \\ \text { PKA } & \text { Protein kinase A } \\ \text { SNP } & \text { Single nucleotide polymorphism }\end{array}$

\section{Introduction}

The recent advent of the genome-wide association studies of type 2 diabetes and its associated traits has proved to be a tremendous breakthrough in diabetes and metabolic research $[1,2]$. These studies have produced lists of genes, many of which were not suspected to be associated with the disease, to which the research field now needs to shift its attention. The great majority of these genes appear to be mainly implicated in beta cell function. In this review, we describe the unexpected discovery that a well-known hormone-melatonin - which has previously been implicated in the control of seasonal and circadian rhythms may be an important player in the events leading to the development of type 2 diabetes. To place this discovery into context, we will briefly outline the principles of biological rhythm, summarise the biology of melatonin-a 
key component of the system - and describe what is known about the link between melatonin, its receptors, and the pathogenesis of type 2 diabetes.

\section{Chronobiology, metabolic control and disease}

It was realised as far back as in the eighteenth century that organisms, ranging from unicellular to multicellular, exhibit inherent rhythms. Such rhythmicity plays an important role in the temporal control of a wide range of biological processes in the body, the most notable of which is metabolism [3].

\section{Biological rhythms}

The most important and well-known biological rhythm is the circadian rhythm. The name is derived from the Greek words for around (circa) and day (diem), and is defined as the roughly $24 \mathrm{~h}$ cycle that characterises virtually all organisms on Earth. It is an adaptation to the periodicity at which our planet moves around its axis, which determines day length. In addition to circadian rhythm, there are ultradian rhythms, which are shorter than $24 \mathrm{~h}$, and infradian rhythms, which extend beyond $24 \mathrm{~h}$. To be considered a circadian rhythm, three major criteria must be fulfilled: (1) it should persist under constant external conditions, i.e. endogenously generated; (2) it should be temperature-insensitive; (3) it can be reset by an external stimulus, i.e. entrainment.

\section{Control of circadian rhythm}

Tremendous advances have been made in recent years in the understanding of how circadian rhythms are controlled [3]. A complex of the transcription factors referred to as circadian locomotor output cycles kaput (CLOCK) and brain and muscle aryl hydrocarbon receptor nuclear translocator (ARNT)-like 1 (BMAL1) controls the Period (PER) genes. This offsets oscillating feedback loops of transcription and translation, which generate waves of gene expression with a periodicity of $24 \mathrm{~h}$. While this machinery is endogenously generated, it is entrained by external stimuli, of which light is perhaps the most critical one. It is also sensitive to signals from metabolism, e.g. cellular redox state has been shown to affect CLOCK activity [4]. The system is hierarchical, the suprachiasmatic nucleus in the hypothalamus being the 'master clock', with additional clock activities in numerous peripheral tissues. In fact, there is some evidence for a circadian rhythm in pancreatic islets [5]. The peripheral clocks are all thought to signal back to the 'master clock' in the suprachiasmatic nucleus.
Disruption of circadian rhythm and metabolic disease

Given the intimate relationship between circadian rhythms and metabolism, a link between the disruption of circadian rhythm and metabolic perturbation has been considered [3]. Indeed, the metabolic syndrome is more prevalent in shift workers [6], known to exhibit disturbances of circadian rhythm, and sleep-deprivation has been associated with both obesity and type 2 diabetes [7]. Moreover, when circadian rhythm is experimentally misaligned in humans, a profound effect on both plasma insulin and glucose levels, promoting glucose intolerance, is observed [8].

\section{Melatonin}

The hormone melatonin is an integral part of the homeostatic mechanisms in the body. It signals whether light or dark prevails. Melatonin is a critical 'zeitgeber', i.e. a cue entraining clock mechanisms in various parts of the body. In this capacity, many of the effects of melatonin can be sought.

\section{Structure and synthesis}

Melatonin, like the neurotransmitter serotonin, is an indoleamine. It is converted in two steps from the amino acid tryptophan into serotonin (5-hydroxytryptamine, 5-HT), and then acetylated by arylalkylamine $N$-acetyltransferase (AANAT), the rate-limiting step in melatonin biosynthesis, before finally being converted into melatonin by hydroxyindole- $O$-methyl transferase [9].

\section{Localisation of melatonin}

The hormone is mainly secreted by endocrine cells (pinealocytes) in the pineal gland, which is located in the midline of the brain, just above the posterior commissure at the dorsal edge of the third ventricle. Melatonin remains detectable after pinealectomy in some species [10], and subsequent investigations revealed that the hormone is produced by neuroendocrine cells in the retina, Harderian glands, gastrointestinal tract and pancreas [11]. Melatonin is also produced by numerous non-endocrine cells, e.g. immune cells. Hence, while the pineal gland quantitatively accounts for the circulating pool of the hormone, substantial local synthesis also occurs in retina and peripheral tissues such as the gastrointestinal tract.

Pineal secretion of melatonin

Because melatonin is stored neither in large dense core nor small synaptic vesicles in the pineal gland [12], melatonin 
is released constitutively [13], the rate of release being determined by the rate of synthesis. The synthesis and subsequent secretion of melatonin are, in most species, regulated by the activity of AANAT. This control is exerted at both the transcriptional and post-translational level, the relative importance of these processes in control being species-dependent.

Central to the control of these processes is stimulation of $\beta_{1}$-adrenergic receptors by noradrenergic input to the pineal gland. This is mainly derived from the superior cervical ganglion, which receives signals from the retina via the suprachiasmatic and paraventricular nuclei in the hypothalamus. In addition, a plethora of inputs that employ the same pathway, as well as circulating transmitters and hormones, are integrated and affect the function of the pinealocytes and the release of melatonin [14].

The $\beta_{1}$-adrenergic receptors in the pineal gland activate the protein kinase A (PKA)/cAMP signalling pathway [14]. An important downstream effect of this pathway is the inhibition of the proteasomal degradation of AANAT [15]; this effect appears to be particularly important in humans. It explains why there is actually a very modest daily variation in AANAT mRNA levels in humans, but a prominent rhythm of protein levels and activity. Moreover, PKA phosphorylates the transcription factor cAMP-responsive element binding protein, which activates transcription of AANAT; this process is particularly effective in rodents, in which, at night, there is an approximately 100 -fold increase in pineal gland levels of AANAT mRNA [16]. Furthermore, AANAT is itself subject to phosphorylation by PKA, which enhances its activity [15].

Light entrains the circadian clock, making melatonin production occur during night. Because the onset and offset of melatonin secretion are controlled by the clock, moving closer together in the summer and further apart in winter, the duration of melatonin production varies according to the time of year [17, 18]. However, in the absence of light and in blind people, a circadian rhythm of melatonin secretion persists, and in these cases cycle length is governed by the suprachiasmatic nucleus [19]. Exposure to light at night also has an acute suppressive effect on melatonin production. In rodents, exposure to light at night decreases melatonin within minutes, while mRNA levels for the protein remain high for hours. The withdrawal of noradrenergic input to the pineal gland leads to a loss of the inhibition of proteasomal degradation, and hence light causes the AANAT protein to be rapidly degraded.

These considerations have led to the following model (Fig. 1) for how melatonin is released from the pineal gland $[16,20-22]$ : the circadian clock in the suprachiasmatic nucleus is more active during the day than at night. The neurons in the suprachiasmatic nucleus release $\gamma$ aminobutyric acid (GABA) to inhibit the activity of neurons in the paraventricular nucleus. These neurons drive sympathetic output through the superior cervical ganglion to the pineal gland. At night, neuronal activity in the suprachiasmatic nucleus decreases, and the paraventricular neurons are disinhibited. Consequently, the noradrenergic input to the pineal gland from the superior cervical ganglion increases. The subsequent $\beta$-adrenergic stimulation leads to an increase in the synthesis and release of melatonin because of increased levels and activity of AANAT. Circulating levels of melatonin peak at $\sim 200 \mathrm{pg} / \mathrm{ml}$ in the middle of the night and drop to $\sim 10 \mathrm{pg} / \mathrm{ml}$ during day time; the half-life of the hormone in the circulation is less than $20 \mathrm{~min}$ [20].

\section{Physiological effects of melatonin}

The most well-known role of melatonin is that as a chronobiotic factor or 'zeitgeber', adjusting the timing or reinforcing oscillations of the biological clock, i.e. entrainment [20]. As such, it is thought to participate in the control of seasonal as well as circadian rhythms. This is based on the fact that the secretion of melatonin reflects ambient light and normally exhibits a tightly regulated diurnal patternfor this reason melatonin is sometimes called 'the hormone of darkness'. Disruptions may occur in individuals deprived of light, e.g. shift workers or travellers across time zones. On a daily basis, melatonin has a small modulatory effect on the pacemaker activity of the circadian clock in the suprachiasmatic nucleus. On a seasonal basis, the varying lengths of the peaks and troughs of the circulating levels of melatonin follow the changes in the duration of daylight. The seasonal regulation of the nocturnal secretory duration is the primary cue regulating reproductive function in mammals that breed seasonally.

Melatonin also affects the cardiovascular system [23] and interacts with the immune system [24]. It has also been implicated in metabolic control [25]. Given that the sites of melatonin production are widespread, effects may be both endocrine, via melatonin released from the pineal gland, and paracrine/autocrine, via melatonin released in the vicinity of its target tissues [26].

An interesting feature of melatonin is its capacity to act as an antioxidant, owing to its chemical structure. However, melatonin does not undergo redox cycling, i.e. repeated oxidation and reduction, but is instead a terminal or suicidal antioxidant [27].

Pharmacological use of melatonin

The phase-advancing effects of melatonin have frequently been exploited [28], with the hormone proven to be effective in the treatment of insomnia $[29,30]$ and efficient in limiting jet lag when travelling across time zones [31]. 


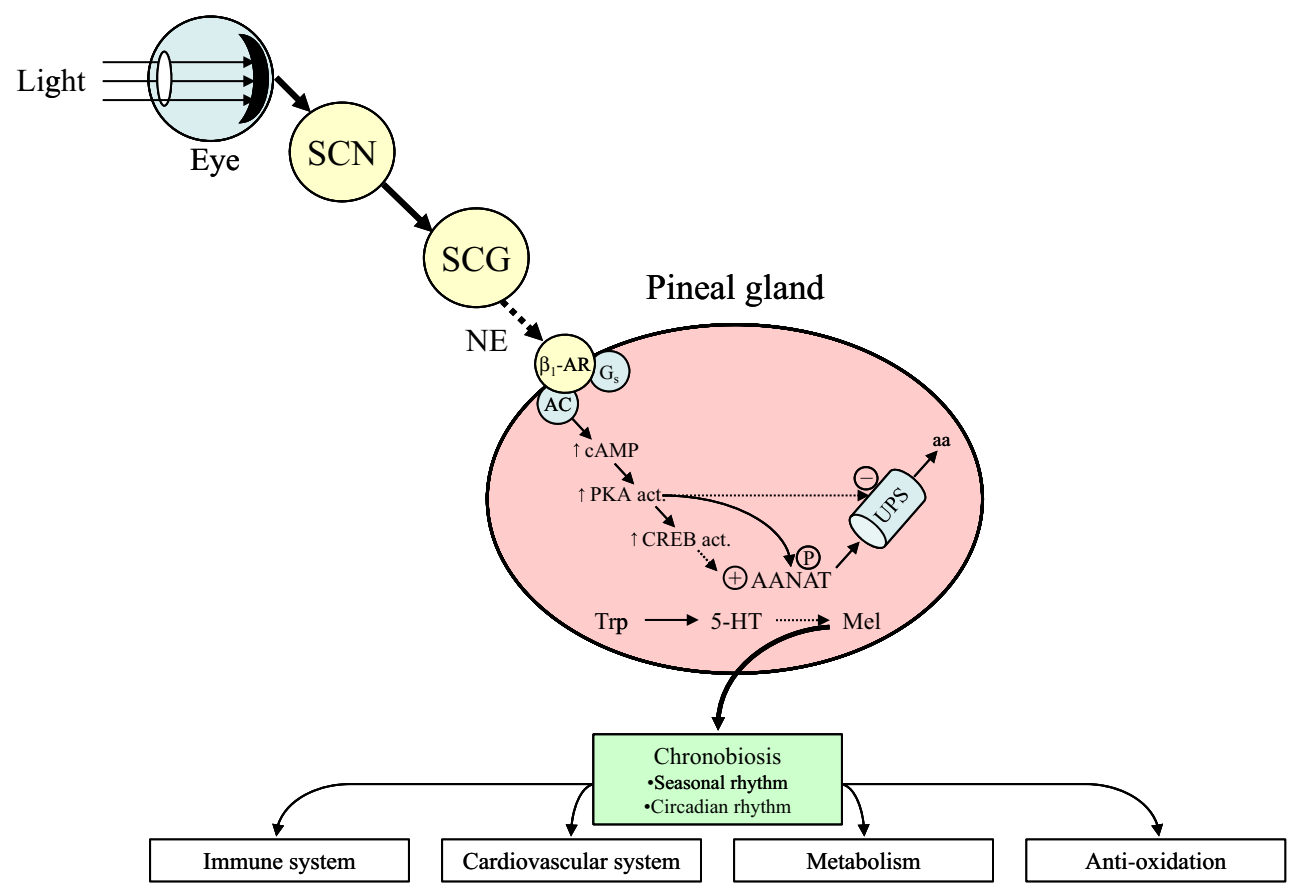

Fig. 1 Regulation of melatonin release from the pineal gland. The circadian clock in the suprachiasmatic nucleus $(\mathrm{SCN})$ is controlled by retinal photoreceptors activated by light. During night time, the noradrenergic (NE) input to the pineal gland from the superior cervical ganglion (SCG) increases. Activation of $\beta_{1}$-adrenergic receptors $\left(\beta_{1}\right.$ AR) coupled to stimulatory $G$ proteins $\left(G_{\mathrm{s}}\right)$ subsequently activates adenylate cyclase (AC), leading to an increase in cellular cAMP levels. Protein kinase A (PKA) becomes activated. This results in the inhibition of the ubiquitin proteasomal system (UPS), which, when active, degrades serotonin- $N$-acetyl transferase (AANAT), which

The administration of melatonin promotes both phase advancement and resynchronisation of the biological clock.

\section{Melatonin receptors}

Structure of melatonin receptors

There is a family consisting of three melatonin receptor subtypes that belong to the class of $\mathrm{G}$ protein-coupled receptors [32]; two functional melatonin receptors are found in mammals. The human gene names MTNR1A and MTNR1B correspond to $\mathrm{Mel}_{1 \mathrm{a}}$ (or MT1) and $\mathrm{Mel}_{1 \mathrm{~b}}$ (or MT2) receptors, respectively, in rodents.

Signal transduction of melatonin

Melatonin inhibits the accumulation of cAMP [33, 34] and exerts most of its effects in a pertussis toxin-sensitive fashion [35]. This implies that the melatonin receptor(s) is coupled to an inhibitory $\mathrm{G}$ protein $\left(\mathrm{G}_{\mathrm{i}}\right)$; however, a cholera toxin-sensitive action has also been observed [36], indi- catalyses the rate-limiting step in melatonin biosynthesis. In addition, PKA phosphorylates and activates the cAMP-responsive element binding protein (CREB), which leads to transcriptional activation of the gene encoding AANAT. The AANAT protein is also phosphorylated and activated by PKA. All these processes, albeit to variable degrees in different species, increase the activity of AANAT and, hence, increase the rate of synthesis and release of melatonin. The dotted lines indicate that steps have been omitted. aa, amino acids; act., activation; 5-HT, 5-hydroxytryptamine (i.e. serotonin); mel, melatonin

cating coupling to $\mathrm{G}_{0}$. The most prominent response to melatonin receptor occupation is inhibition of adenylate cyclase, leading to a fall in cellular cAMP levels [32]. Melatonin receptor 1A (MTNR1A), but possibly not MTNR1B, also affects phospholipase C (PLC) activity, promoting the formation of inositide phosphates and arachidonic acid [37], and possibly diacylglycerol. MTNR1B, but not 1A, has been shown to inhibit formation of cGMP, via the soluble guanylate cyclase pathway [38]. In vitro, MTNR1A associates with $\mathrm{G}_{\mathrm{i} 2}$ and $\mathrm{G}_{\mathrm{i} 3}$, which results in the inhibition of adenylate cyclase, and $\mathrm{G}_{\mathrm{q} / 11}$, which activates the PLC pathway [39, 40].

Distribution of melatonin receptors

The great majority of melatonin receptors are found in the brain [32]. MTNR1A is vastly more abundant than MTNR1B. In most species, MTNR1A mRNA is found in the suprachiasmatic and paraventricular nuclei of the hypothalamus, and the pars tuberalis of the pituitary. Mtnr $1 b$ mRNA occurs in the suprachiasmatic nucleus and the hippocampus in rodents; it has also been detected in human retina and brain. 


\section{Melatonin and glucose homeostasis}

Circulating insulin and melatonin levels

Nocturnal levels of the anabolic hormone insulin are lowsince humans are programmed not to eat during the night, there will be little need for insulin, which controls metabolism in the postprandial and anabolic states. In fact, an excess of insulin could have detrimental effects on the central nervous system if hypoglycaemia were to occur. Because melatonin is a biological signal of darkness [32] and, consequently, reduced metabolism, it has been proposed that melatonin could contribute to the nocturnal lowering of insulin in humans.

That insulin secretion is controlled by circadian mechanisms is supported by studies of humans with circadian misalignment, who are reported to show profound perturbations of plasma glucose and insulin levels [8]. The concept is supported by the assumption that there is a circadian clock in pancreatic islets [5]. While it is clear that insulin secretion exhibits a circadian rhythm, it is unclear whether secretion increases or decreases during the night [41, 42].

There are indications that the diurnal secretion of melatonin is altered in diabetes, particularly when neuropathy is evident [43]. Peschke et al. [44] reported reduced circulating levels of melatonin and elevated levels of insulin in type 2 diabetic patients, with a statistically significant negative correlation found between the two. No information on treatment or disease duration was given in this study [44], but the increased levels of insulin suggest that the patients did not suffer from advanced insulin-requiring type 2 diabetes. Similarly, nocturnal melatonin levels are reduced in the Goto-Kakizaki (GK) rat, a model of type 2 diabetes [44]. Confusingly, animal models of type 1 diabetes, i.e. streptozotocin- and alloxan-treated rodents, exhibit either elevated [45] or decreased [46] levels of melatonin. Data from rodent studies are both contradictory and difficult to interpret with respect to melatonin and metabolism, given that these species eat during the subjective night time.

Altering melatonin action in vivo

Effects of pinealectomy One way of reducing melatonin levels in vivo is to perform a pinealectomy. For obvious reasons, this is a major perturbation, which largely abolishes circulating melatonin. Moreover, the time at which the samples are drawn also has a major effect on the outcome of the study. Experiments of this kind are therefore difficult to interpret, and, indeed, the results from many of these studies are contradictory [25]. The more recent studies suggest that the removal of melatonin by pinealectomy in rodents leads to an increase in plasma glucose levels and a decrease in plasma insulin levels [47], particularly during night time [48].

Effects of exogenous melatonin Melatonin has been shown to inhibit insulin secretion in the rat and mouse [49]. Nevertheless, chronic administration of melatonin ameliorates metabolic perturbations in Otsuka Long-Evans Tokushima Fatty rats, including hyperinsulinaemia [50]; it is unclear whether this is a direct or indirect effect, and whether melatonin acts in this way under physiological conditions. These seemingly inconsistent results could be attributed to different time courses for melatonin administration; clearly, this is of paramount importance, given the short half-life of the hormone and the requirements for rhythmicity. Also, the time of day the experiments or measurements are performed would profoundly affect the results.

Effects of insulin on melatonin It has been argued that insulin itself controls the production and subsequent release of melatonin [25]. This argument is difficult to resolve, given the many effects induced by insulin, which secondarily may affect the pineal gland. The concept is supported by the finding of Ins mRNA in the pineal gland [45]. Indeed, both glucose and insulin reduce adrenaline (epinephrine)-induced melatonin secretion from perifused pineal glands [45]. Although it is likely that the pineal gland is exposed to circulating insulin, given that it is localised outside the blood-brain barrier [20], the identity of the cells that harbour the insulin receptor has not yet been determined.

\section{Melatonin and insulin secretion}

Melatonin receptors in pancreatic islets and beta cells

If melatonin has direct effects on insulin secretion, its receptors should be present in islets of Langerhans, preferably beta cells. This indeed appears to be the case, as inferred from studies using the non-hydrolysable GTP analogue guanosine $5^{\prime}-O$-(3-thiotriphosphate) and the melatonin antagonist luzindole [51], both of which block the effects of melatonin on insulin secretion from neonatal rat islets. MTNR1A mRNA was subsequently demonstrated in INS-1 cells $[52,53]$ and in rat $[54,55]$ and human islets [55]. MTNR1B mRNA has also been detected in rat [54, 55] and human islets [55], but at levels several-fold lower than those of MTNR1A mRNA. MIN-6 cells also express both forms of the receptor [55]. In human islets, MTNR1A mRNA occurs primarily in alpha cells [55], and the level of $M T N R 1 B$ mRNA is lower than that of MTNR1A mRNA. 
We were able to confirm that rodent and human islets contain mRNA for both types of melatonin receptor [56]. However, contrary to previous findings $[54,55]$, we found that the differences between the levels of the receptor mRNAs were not as big as in human islets [56]. We also observed that the MTNR1B protein predominantly occurs in beta cells in either human or rodent islets; MTNR1A protein is found in peripherally located beta cells.

\section{Melatonin and insulin secretion}

The existing literature implies that melatonin inhibits insulin secretion from pancreatic beta cells [25], although there are reports of no effect [57] or a stimulatory effect [58].

Melatonin as an inhibitor of insulin secretion in isolated islets and beta cells Melatonin attenuates glucose- and $\mathrm{KCl}$-stimulated insulin secretion from perifused rat islets [59]. The inhibitory effect of melatonin on insulin release from rat islets was later confirmed [60]. Melatonin stimulates the release of glucagon from perifused human islets [55]; insulin release was also stimulated, presumably indirectly through glucagon. The inhibitory effects of melatonin on insulin secretion have been replicated in clonal beta cells $[53,55,56,58]$.

Signal transduction of melatonin in islets and beta cells An insulinostatic effect of melatonin is consistently observed for insulin release potentiated by agents that elevate cAMP levels (Fig. 2). This is in line with the coupling of MTNR1A and MTNR1B to $G_{i}$ [32] and, indeed, it was found that melatonin is particularly effective at abrogating the potentiation of insulin secretion by forskolin [53] or glucagon-like peptide 1 [52]. Furthermore, the application of melatonin blocks the efflux of cAMP from INS-1 cells, presumably reflecting decreased formation of cAMP [53] or the activity of a cAMP-response element (CRE) construct [52]. Interestingly, prolonged pretreatment of either INS-1 cells or rat islets with melatonin potentiates the secretory response to cAMP-raising agents [52]. In contrast, melatonin does not affect cAMP levels in human islets, whereas the formation of cAMP in MIN-6 cells is impaired, as is insulin secretion in response to melatonin [55].

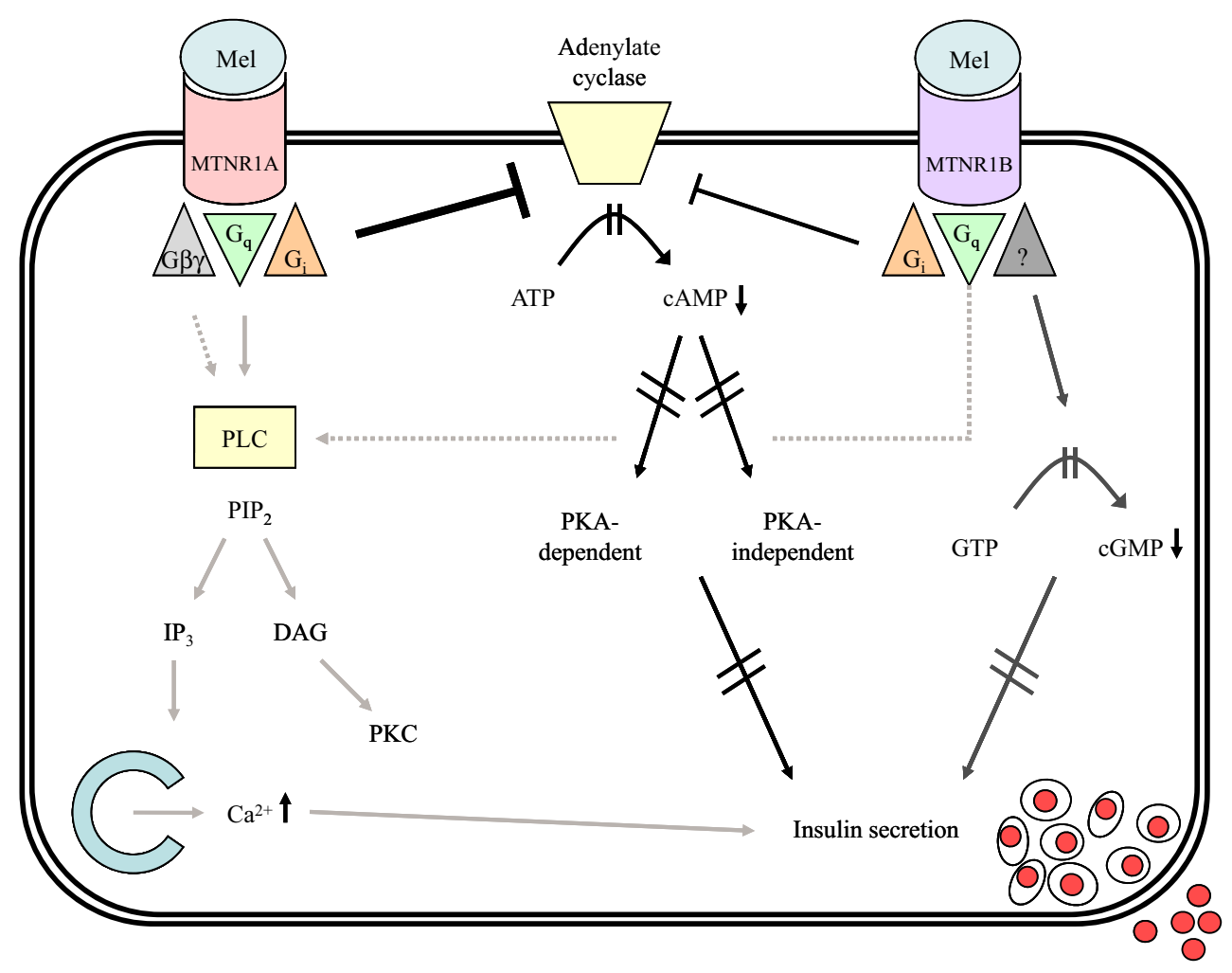

Fig. 2 Melatonin receptor signalling in pancreatic beta cells. Both melatonin receptors (MTNR1A and MTNR1B) are G proteincoupled receptors and are expressed in pancreatic beta cells. Both receptors are coupled to a $G_{i}$, which inactivates adenylate cyclase, and lowers cAMP levels in the cell, which results in reduced insulin secretion. This effect is mainly a result of MTNR1A signalling. MTNR1A is also coupled to $\mathrm{G}_{\mathrm{q}}$, which activates PLC, cleaving phosphatidylinositol-4,5-biphosphate ( $\mathrm{PIP}_{2}$ ) into inositol-1,4,5triphosphate $\left(\mathrm{IP}_{3}\right)$ and diacylglycerol (DAG), and the $\mathrm{IP}_{3}$ stimulates calcium release from the endoplasmic reticulum. In contrast, this signalling pathway has an enhancing effect on insulin secretion, and has been suggested to be mediated by MTNR1B as well. MTNR1B signalling inhibits cGMP formation, reducing insulin secretion in the pancreatic beta cell. PKC, protein kinase $\mathrm{C}$ 
Activation of MTNR1B inhibits the formation of cGMP [38], and addition of melatonin to INS-1 cells decreases cellular levels of cGMP, paralleling the impairment of insulin secretion [61]. MTNR1A has also been implicated in signalling controlled by PLC [37], possibly via coupling to $\mathrm{G}_{\mathrm{q} / 11}$ [39]. It has been reported that stimulation of INS-1 cells with melatonin provokes the release of inositol 1,4, 5-triphosphate $[58,62]$, and when $\mathrm{G}_{\mathrm{i}}$ coupling is blocked by pertussis toxin, a stimulatory effect of melatonin is uncovered [58].

\section{Genome-wide association studies and MTNR1B}

In view of the effects of melatonin on islets and on whole body metabolism, a link between melatonin receptors and type 2 diabetes was suggested [63] following the demonstration of increased levels of MTNR1A and MTNR1B mRNA in pancreatic tissue from patients with type 2 diabetes and increased immunolabelling of MTNR1A and MTNR1B. Although these results were qualitative rather than quantitative, it was postulated that there is a link between the melatonin system and the pathogenesis of the disease. While an association between MTNR $1 A$ and type 2 diabetes has not been confirmed in the recently performed genome-wide association studies [56, 64, 65], there is now strong support for associations of genetic variation in the $M T N R 1 B$ locus with fasting glucose levels, insulin secretion and type 2 diabetes. In fact, two different single nucleotide polymorphisms (SNPs; rs1387153 and rs10830963) in MTNR1B were reported to be associated with type 2 diabetes, and there appear to be additional SNPs in this gene that show a similar association [65]. Although rs10830963 maps to within the single $11.5 \mathrm{~kb}$ intron of MTNR1B, it does not interfere with the binding of consensus transcription factors or with splicing [65]. Thus, it is likely that the SNPs reported to be associated with MTNR $1 B$ tag the same signal. Very recently, associations of rs10830963 with elevated fasting plasma glucose and future risk of type 2 diabetes was confirmed in a Chinese population [66].

All recently published articles on the variation in $M T N R 1 B$ report an association with elevated fasting plasma glucose [56, 64-66]. This appears to be accounted for by impaired beta cell function; we demonstrated that this is reduced in the early phase of insulin secretion [56], while another report indicated impaired beta cell function as assessed by HOMA (HOMA-B) [65]. Deterioration of glucose-stimulated insulin secretion over time in carriers of the risk allele was reported in the Botnia prospective study [56]. Moreover, all three reports find that variations in $M T N R 1 B$ are associated with $[64,65]$ or predict future type
2 diabetes [56] with an odds ratio ranging between 1.09 and 1.20. This may seem a modest increase in risk, but it is, in fact, of a similar magnitude to those previously reported for other genes associated with an increased risk of type 2 diabetes. It emphasises that common type 2 diabetes is a polygenic disease, whereby each gene makes a variable, often small, contribution to the overall risk. Indeed, it has been shown that carriers of several risk variants are subject to an additive risk of developing the disease [64]. Moreover, the risk allele of $M T N R 1 B$ appears to be relatively unique among genes affecting fasting plasma glucose in that it also is significantly associated with future

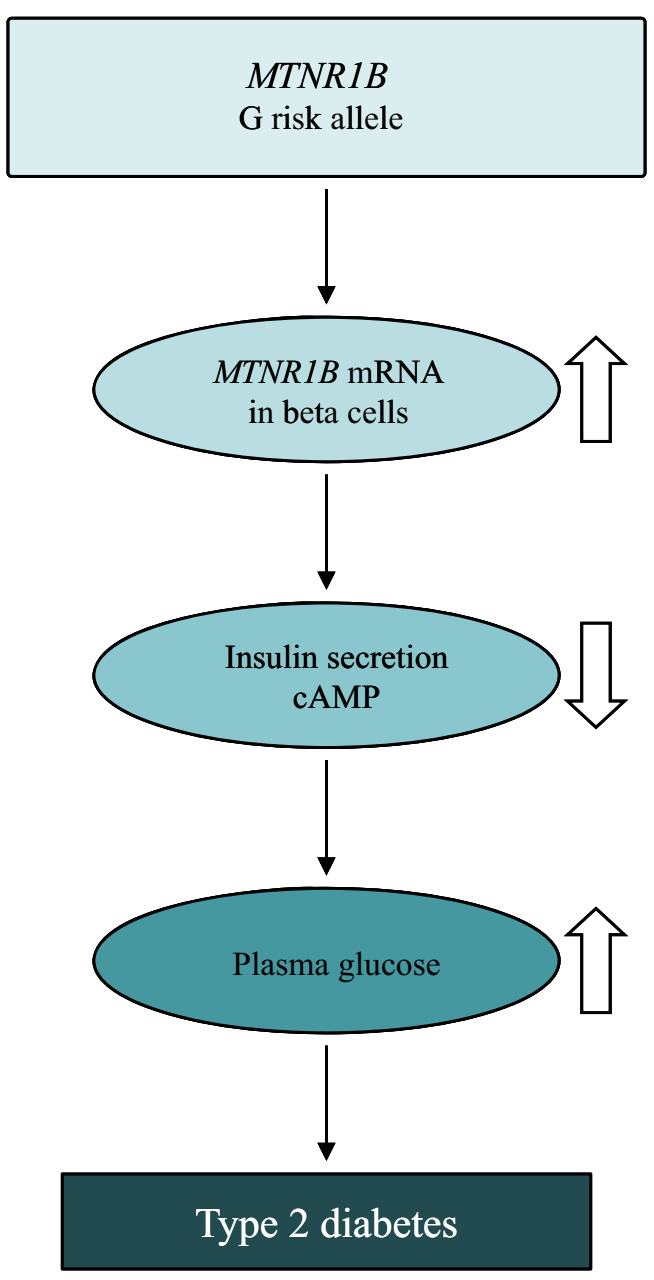

Fig. 3 Proposed pathogenetic mechanism for altered melatonin signalling in type 2 diabetes. In individuals carrying the risk allele (G) in MTNRIB, there is an increased level of mRNA for this subtype of melatonin receptor in pancreatic beta cells. Consequently, the effect of melatonin on the beta cell may be exaggerated, leading to a decrease in cAMP levels, since the receptor is coupled to a $G_{i}$. In the event that cAMP levels decrease in the beta cells, the insulinotropic pressure, e.g. that exerted by glucagon-like peptide 1, may be diminished. This could potentially result in a decrease in the amount of insulin secreted, and hence contribute to elevated fasting plasma glucose, lower circulating insulin levels, and the increased risk of type 2 diabetes observed in carriers of the SNPs rs10830963 and/or rs 1387153 
risk of type 2 diabetes [56, 64, 65]; most of the previously described candidate genes for type 2 diabetes do not affect fasting plasma glucose, once people with subclinical diabetes are excluded from the analysis.

We demonstrated that both MTNRIB mRNA and the protein occur in human islets, predominantly beta cells [56]. This was confirmed by the finding that sorted human beta cells and islets contain identical mRNA species [64]. Clearly, the SNPs in MTNRIB that are associated with, for example, type 2 diabetes, may in themselves not be pathogenic, but, rather, serve as markers for an allele linked to the disease. However, levels of MTNRIB mRNA in islets from carriers of a GG genotype are higher in individuals older than 45 years, and a trend for increased levels of the receptor mRNA in islets from type 2 diabetic patients is also evident [56]. This strongly suggests that MTNR1B is responsible for the increased risk of type 2 diabetes in carriers of the risk allele. Ongoing sequencing of MTNR1B will hopefully reveal pathogenic sequence alterations.

\section{Pathogenetic implications of the association between $M T N R 1 B$ and type 2 diabetes}

In this review we have described some aspects of the endocrine system based on melatonin, which may be relevant for the control of metabolic homeostasis and, possibly, the development of type 2 diabetes. That alterations in MTNR1B are, beyond doubt, linked to an increased risk of type 2 diabetes $[56,64,65]$ - the level of statistical significance is very high-but the precise nature of the link remains to be clarified.

The work performed to date does provide some clues (Fig. 3). We described how levels of MTNRIB mRNA are increased in older carriers of the risk allele [56]. Given that most of the available data support a direct inhibitory effect of melatonin on insulin secretion [25], an at-risk individual may thus be more sensitive to the inhibitory effect of melatonin than an individual without the risk allele, who would have a normal islet level of MTNR1B. Such a restraining effect of melatonin is in line with the impairment of early phase insulin secretion [56] and reduced HOMA-B [65] observed in carriers of the risk allele. The possibility that perturbed rhythmic secretion of melatonin could contribute to disease development is intriguing and deserves further study in type 2 diabetes. Also, the effect of melatonin on insulin secretion, particularly in human islets, needs more attention. In fact, there is a well-established link between sleep disorders and risk of type 2 diabetes [67]. It will be of interest to explore whether genetic variations in MTNR1B explain this connection, at least in part. Some of the emerging scientific questions that need to be answered are given in the text box.
Scientific challenges-melatonin, its receptors and type 2 diabetes

- Sequencing of MTNR1B in patients with type 2 diabetes

- Melatonin secretion in type 2 diabetes Diurnal rhythm

- Effect of insulin on melatonin release

- Sleep disorders, type 2 diabetes and the metabolic syndrome

- Effect of melatonin antagonism in glucose homeostasis

- Metabolic phenotype of murine mutants for melatonin receptors

- Islets: analysis in vitro

Effects of melatonin in human islets insulin secretion beta cell mass alpha cells vs beta cells

Signal transduction of melatonin receptors human islets rodent islets clonal beta cells

Production of melatonin in islets expression of $A A N A T$ and HIOMT molecular characterisation of melatonin (liquid chromatography/tandem mass spectrometry)

Melatonin effects on $C L O C K /$ related genes in islets

Time will tell whether MTNR1B antagonists may serve as therapeutic agents in type 2 diabetes. The option of blocking the effect of melatonin in islets is an attractive possibility. However, an islet-specific attenuation of melatonin action may be required, since it can be envisioned that the systemic effects of MTNR1B blockade may be disadvantageous. Nevertheless, the discovery of the link between MTNRIB and type 2 diabetes re-emphasises the importance of biological rhythm for metabolic regulation.

Acknowledgements The authors thank all co-authors of the article on which we have collaborated [56], and D. R. Weaver at the University of Massachusetts Medical School, who provided feedback on this review. Work by the authors described here was supported by a Linneaus grant from the Swedish Research Council (60023701), as well as several other grants from the Swedish Research Council (to $\mathrm{H}$. Mulder 14196, L. Groop 10858), an equipment grant from the Wallenberg Foundation, and by the European Foundation for the Study of Diabetes/MSD (to H. Mulder), the Crafoord and Albert Påhlsson Foundations, the Swedish Diabetes Association, and the Faculty of Medicine at Lund University. 
Duality of interest L. Groop has been a consultant and served on advisory boards for sanofi-aventis, GSK, Novartis, Merck, Tethys Bioscience and Xoma. He has received lecture fees from Lilly and Novartis. The authors declare that there is no duality of interest associated with this manuscript.

\section{References}

1. Ridderstråle M, Groop L (2009) Genetic dissection of type 2 diabetes. Mol Cell Endocrinol 297:10-17

2. Doria A, Patti ME, Kahn CR (2008) The emerging genetic architecture of type 2 diabetes. Cell Metab 8:186-200

3. Green CB, Takahashi JS, Bass J (2008) The meter of metabolism. Cell 134:728-742

4. Rutter J, Reick M, McKnight SL (2002) Metabolism and the control of circadian rhythms. Annu Rev Biochem 71:307-331

5. Peschke E, Peschke D (1998) Evidence for a circadian rhythm of insulin release from perifused rat pancreatic islets. Diabetologia 41:1085-1092

6. Karlsson B, Knutsson A, Lindahl B (2001) Is there an association between shift work and having a metabolic syndrome? Results from a population based study of 27,485 people. Occup Environ Med 58:747-752

7. Knutson KL, Ryden AM, Mander BA, van Cauter E (2006) Role of sleep duration and quality in the risk and severity of type 2 diabetes mellitus. Arch Intern Med 166:1768-1774

8. Scheer FA, Hilton MF, Mantzoros CS, Shea SA (2009) Adverse metabolic and cardiovascular consequences of circadian misalignment. Proc Natl Acad Sci U S A 106:4453-4458

9. Axelrod J, Weissbach H (1960) Enzymatic $O$-methylation of $N$ acetylserotonin to melatonin. Science 131:1312

10. Ozaki Y, Lynch HJ (1976) Presence of melatonin in plasma and urine or pinealectomized rats. Endocrinology 99:641-644

11. Kvetnoy IM (1999) Extrapineal melatonin: location and role within diffuse neuroendocrine system. Histochem J 31:1-12

12. Tricoire H, Moller M, Chemineau P, Malpaux B (2003) Origin of cerebrospinal fluid melatonin and possible function in the integration of photoperiod. Reprod Suppl 61:311-321

13. Hirota T, Kagiwada S, Kasahara T, Okano T, Murata M, Fukada Y (2001) Effect of brefeldin A on melatonin secretion of chick pineal cells. J Biochem 129:51-59

14. Simonneaux V, Ribelayga C (2003) Generation of the melatonin endocrine message in mammals: a review of the complex regulation of melatonin synthesis by norepinephrine, peptides, and other pineal transmitters. Pharmacol Rev 55:325-395

15. Gastel JA, Roseboom PH, Rinaldi PA, Weller JL, Klein DC (1998) Melatonin production: proteasomal proteolysis in serotonin $\mathrm{N}$-acetyltransferase regulation. Science 279:1358-1360

16. Iuvone PM, Tosini G, Pozdeyev $N$, Haque R, Klein DC, Chaurasia SS (2005) Circadian clocks, clock networks, arylalkylamine $N$-acetyltransferase, and melatonin in the retina. Prog Retin Eye Res 24:433-456

17. Illnerova H, Sumova A (1997) Photic entrainment of the mammalian rhythm in melatonin production. J Biol Rhythms 12:547-555

18. Wehr TA (2001) Photoperiodism in humans and other primates: evidence and implications. J Biol Rhythms 16:348-364

19. Klerman EB, Shanahan TL, Brotman DJ et al (2002) Photic resetting of the human circadian pacemaker in the absence of conscious vision. J Biol Rhythms 17:548-555

20. Arendt J (1994) Melatonin and the mammalian pineal gland. Chapman and Hall, London

21. Goldman BD (1999) The circadian timing system and reproduction in mammals. Steroids 64:679-685

22. Kalsbeek A, Palm IF, La Fleur SE et al (2006) SCN outputs and the hypothalamic balance of life. J Biol Rhythms 21:458-469
23. Krause DN, Geary GG, Doolen S, Duckles SP (1999) Melatonin and cardiovascular function. Adv Exp Med Biol 460:299-310

24. Reiter RJ, Calvo JR, Karbownik M, Qi W, Tan DX (2000) Melatonin and its relation to the immune system and inflammation. Ann N Y Acad Sci 917:376-386

25. Peschke E (2008) Melatonin, endocrine pancreas and diabetes. J Pineal Res 44:26-40

26. Kvetnoy I, Sandvik AK, Waldum HL (1997) The diffuse neuroendocrine system and extrapineal melatonin. J Mol Endocrinol 18:1-3

27. Tan DX, Manchester LC, Reiter RJ, Qi WB, Karbownik M, Calvo JR (2000) Significance of melatonin in antioxidative defense system: reactions and products. Biol Signals Recept 9:137-159

28. Redman JR (1997) Circadian entrainment and phase shifting in mammals with melatonin. J Biol Rhythms 12:581-587

29. Zhdanova IV, Wurtman RJ (1997) Efficacy of melatonin as a sleep-promoting agent. J Biol Rhythms 12:644-650

30. Arendt J (2006) Does melatonin improve sleep? Efficacy of melatonin. BMJ 332:550

31. Arendt J, Skene DJ, Middleton B, Lockley SW, Deacon S (1997) Efficacy of melatonin treatment in jet lag, shift work, and blindness. J Biol Rhythms 12:604-617

32. von Gall C, Stehle JH, Weaver DR (2002) Mammalian melatonin receptors: molecular biology and signal transduction. Cell Tissue Res 309:151-162

33. Abe K, Robison GA, Liddle GW, Butcher RW, Nicholson WE, Baird CE (1969) Role of cyclic AMP in mediating the effects of $\mathrm{MSH}$, norepinephrine, and melatonin on frog skin color. Endocrinology 85:674-682

34. Vanecek J (1998) Cellular mechanisms of melatonin action. Physiol Rev 78:687-721

35. White BH, Sekura RD, Rollag MD (1987) Pertussis toxin blocks melatonin-induced pigment aggregation in Xenopus dermal melanophores. J Comp Physiol [B] 157:153-159

36. Morgan PJ, Williams LM, Barrett P et al (1996) Differential regulation of melatonin receptors in sheep, chicken and lizard brains by cholera and pertussis toxins and guanine nucleotides. Neurochem Int 28:259-269

37. Godson C, Reppert SM (1997) The Mella melatonin receptor is coupled to parallel signal transduction pathways. Endocrinology 138:397-404

38. Petit L, Lacroix I, de Coppet P, Strosberg AD, Jockers R (1999) Differential signaling of human Mella and Mellb melatonin receptors through the cyclic guanosine 3'-5'-monophosphate pathway. Biochem Pharmacol 58:633-639

39. Brydon L, Roka F, Petit L et al (1999) Dual signaling of human Mella melatonin receptors via $\mathrm{G}_{\mathrm{i} 2}, \mathrm{G}_{\mathrm{i} 3}$, and $\mathrm{G}_{\mathrm{q} / 11}$ proteins. Mol Endocrinol 13:2025-2038

40. Roca AL, Godson C, Weaver DR, Reppert SM (1996) Structure, characterization, and expression of the gene encoding the mouse Mel1a melatonin receptor. Endocrinology 137:3469-3477

41. van Cauter E, Blackman JD, Roland D, Spire JP, Refetoff S, Polonsky KS (1991) Modulation of glucose regulation and insulin secretion by circadian rhythmicity and sleep. J Clin Invest 88:934-942

42. Boden G, Ruiz J, Urbain JL, Chen X (1996) Evidence for a circadian rhythm of insulin secretion. Am J Physiol 271:E246E252

43. O'Brien IA, Lewin IG, O'Hare JP, Arendt J, Corrall RJ (1986) Abnormal circadian rhythm of melatonin in diabetic autonomic neuropathy. Clin Endocrinol (Oxf) 24:359-364

44. Peschke E, Frese T, Chankiewitz E et al (2006) Diabetic Goto Kakizaki rats as well as type 2 diabetic patients show a decreased diurnal serum melatonin level and an increased pancreatic melatonin-receptor status. J Pineal Res 40:135-143 
45. Peschke E, Wolgast S, Bazwinsky I, Ponicke K, Muhlbauer E (2008) Increased melatonin synthesis in pineal glands of rats in streptozotocin induced type 1 diabetes. J Pineal Res 45:439-448

46. Pang SF, Tang F, Tang PL (1985) Alloxan-induced diabetes and the pineal gland: differential effects on the levels of pineal $\mathrm{N}$ acetylserotonin, pineal melatonin, and serum melatonin. J Pineal Res 2:79-85

47. Diaz B, Blazquez E (1986) Effect of pinealectomy on plasma glucose, insulin and glucagon levels in the rat. Horm Metab Res 18:225-229

48. la Fleur SE, Kalsbeek A, Wortel J, van der Vliet J, Buijs RM (2001) Role for the pineal and melatonin in glucose homeostasis: pinealectomy increases night-time glucose concentrations. J Neuroendocrinol 13:1025-1032

49. Bailey CJ, Atkins TW, Matty AJ (1974) Melatonin inhibition of insulin secretion in the rat and mouse. Horm Res 5:21-28

50. Nishida S, Segawa T, Murai I, Nakagawa S (2002) Long-term melatonin administration reduces hyperinsulinemia and improves the altered fatty-acid compositions in type 2 diabetic rats via the restoration of $\Delta-5$ desaturase activity. J Pineal Res 32:26-33

51. Peschke E, Fauteck JD, Musshoff U, Schmidt F, Beckmann A, Peschke D (2000) Evidence for a melatonin receptor within pancreatic islets of neonate rats: functional, autoradiographic, and molecular investigations. J Pineal Res 28:156-164

52. Kemp DM, Ubeda M, Habener JF (2002) Identification and functional characterization of melatonin Mel 1a receptors in pancreatic beta cells: potential role in incretin-mediated cell function by sensitization of cAMP signaling. Mol Cell Endocrinol 191:157-166

53. Peschke E, Muhlbauer E, Musshoff U, Csernus VJ, Chankiewitz E, Peschke D (2002) Receptor $\left(\mathrm{MT}_{1}\right)$ mediated influence of melatonin on cAMP concentration and insulin secretion of rat insulinoma cells INS-1. J Pineal Res 33:63-71

54. Muhlbauer E, Peschke E (2007) Evidence for the expression of both the MT1- and in addition, the MT2-melatonin receptor, in the rat pancreas, islet and beta-cell. J Pineal Res 42:105-106

55. Ramracheya RD, Muller DS, Squires PE et al (2008) Function and expression of melatonin receptors on human pancreatic islets. J Pineal Res 44:273-279

56. Lyssenko V, Nagorny CL, Erdos MR et al (2009) Common variant in MTNRIB associated with increased risk of type 2 diabetes and impaired early insulin secretion. Nat Genet 41:8288

57. Frankel BJ, Strandberg MJ (1991) Insulin release from isolated mouse islets in vitro: no effect of physiological levels of melatonin or arginine vasotocin. J Pineal Res 11:145-148

58. Peschke E, Bach AG, Muhlbauer E (2006) Parallel signaling pathways of melatonin in the pancreatic beta-cell. J Pineal Res 40:184-191

59. Peschke E, Peschke D, Hammer T, Csernus V (1997) Influence of melatonin and serotonin on glucose-stimulated insulin release from perifused rat pancreatic islets in vitro. J Pineal Res 23:156-163

60. Picinato MC, Haber EP, Cipolla-Neto J, Curi R, de Oliveira Carvalho CR, Carpinelli AR (2002) Melatonin inhibits insulin secretion and decreases PKA levels without interfering with glucose metabolism in rat pancreatic islets. J Pineal Res 33:156160

61. Stumpf I, Muhlbauer E, Peschke E (2008) Involvement of the cGMP pathway in mediating the insulin-inhibitory effect of melatonin in pancreatic beta-cells. J Pineal Res 45:318-327

62. Bach AG, Wolgast S, Muhlbauer E, Peschke E (2005) Melatonin stimulates inositol-1,4,5-trisphosphate and $\mathrm{Ca}^{2+}$ release from INS1 insulinoma cells. J Pineal Res 39:316-323

63. Peschke E, Stumpf I, Bazwinsky I, Litvak L, Dralle H, Muhlbauer E (2007) Melatonin and type 2 diabetes - a possible link? J Pineal Res 42:350-358

64. Bouatia-Naji N, Bonnefond A, Cavalcanti-Proenca C et al (2009) A variant near MTNR1B is associated with increased fasting plasma glucose levels and type 2 diabetes risk. Nat Genet 41:8994

65. Prokopenko I, Langenberg C, Florez JC et al (2009) Variants in MTNR1B influence fasting glucose levels. Nat Genet 41:7781

66. Rönn T, Wen J, Yang Z, et al. (2009) A common variant in $M T N R 1 B$, encoding melatonin receptor $1 \mathrm{~B}$, is associated with type 2 diabetes and fasting plasma glucose in Han Chinese individuals. Diabetologia doi:10.1007/s00125-009-1297-8

67. Shaw JE, Punjabi NM, Wilding JP, Alberti KG, Zimmet PZ (2008) Sleep-disordered breathing and type 2 diabetes: a report from the International Diabetes Federation Taskforce on Epidemiology and Prevention. Diabetes Res Clin Pract 81: $2-12$ 